\title{
A Unidade do Psiquismo Humano para Vigotski e a Desagregação desta na Esquizofrenia
}

\author{
Silvana Calvo Tuleski* (DD \\ Universidade Estadual de Maringá, Maringá, PR, Brasil
}

\begin{abstract}
RESUMO - A Psicologia Histórico-Cultural no Brasil teve sua inserção no campo educacional a partir de 1980. Atualmente, os estudos de Vigotski sobre os transtornos mentais vêm sendo explorados, objetivando a compreensão do desenvolvimento psíquico normal e anormal na relação dialética organismo e ambiente sociocultural. Este estudo procura sistematizar tais contribuições referentes à esquizofrenia, focalizando o processo de formação de conceitos e sua desagregação nesta patologia. Busca-se estabelecer comparações e problematizações entre pesquisas atuais sobre fatores de risco, tratamento e sintomatologia do quadro esquizofrênico e as elaborações vigotskianas. Por fim, procura-se apontar caminhos profícuos de superação de visões reducionistas sobre o processo desagregador causador da alienação do sujeito em relação ao mundo e a si mesmo neste transtorno mental.
\end{abstract}

PALAVRAS-CHAVE: esquizofrenia, Vigotski, Psicologia Histórico-Cultural, formação de conceitos

\section{The Unit of Human Psychism as Understood by Vigotski and its Breakdown In Schizophrenia}

\begin{abstract}
Cultural-historical psychology was introduced into the educational field in Brazil starting in 1980. More recently, Vygotsky's studies on mental disorders have been subject to analysis with the aim of understanding normal and abnormal psychic development within the dialectical relation between sociocultural context and organism. This study aimed to outline such contributions related to schizophrenia focusing on the concept formation process and the breakdown of its pathology. We sought to draw questions and comparisons between Vygotskian research and the current research on risk factors, treatment, and symptoms of schizophrenia. Finally, we suggested favorable ways to overcome the reductionist view of the breakdown process which causes the alienation, in this mental disorder, of the subject in relation to the world and to oneself.
\end{abstract}

KEYWORDS: schizophrenia, Vygotsky, cultural-historical psychology, concept formation

A Psicologia Histórico-Cultural ou Escola de Vigotski ficou mais conhecida nos meios educacionais no Brasil a partir da década de 1980. As primeiras obras de Vigotski traduzidas em língua portuguesa foram Pensamento e Linguagem e Formação Social da Mente. Como já amplamente discutido por diversos autores (Duarte, 2000; Prestes, 2010), tais traduções que os educadores brasileiros tiveram acesso inicialmente chegaram editadas, ocasionando inúmeros problemas na compreensão do pensamento deste autor no Brasil.
Por muito tempo, os estudos dos textos dos psicólogos soviéticos, elaboradores da Psicologia Histórico-Cultural, ficaram restritos aos pedagogos, compondo, em parte, disciplinas de sua formação. Apenas gradativamente, em torno de aproximadamente uma década após, ou seja, em finais de 1990, os textos de autores como Vigotski, Luria e Leontiev passaram a ser inseridos nos currículos de Psicologia. Com isso, a Psicologia Histórico-Cultural, em algumas instituições, ganhou o status de uma disciplina específica, ao lado da Psicologia Genética de Jean Piaget, por exemplo, que figurava nos currículos desde 1970.

\footnotetext{
*E-mail: silvanatuleski@gmail.com

- Submetido: 16/06/2016; Avaliado: 03/02/2017; Aceito: 24/02/2018.
} 
Atualmente, temos verificado a ampliação de pesquisas que procuram articular as contribuições dos estudos da Psicologia Histórico-Cultural com a esfera da saúde mental, tais como os de Martins (2002), Berenchtein Netto (2007), Silva (2009), Lima e Carvalho (2013), Almeida e Gomes (2014), Silva (2014), entre outros. Entendemos que há muito ainda a ser realizado nesta direção, principalmente no que se refere à inserção destes estudos nas disciplinas curriculares dos cursos de Psicologia no Brasil. Uma das dificuldades é ter acesso a textos dos autores clássicos, pois diversos deles estão em inglês ou espanhol e muitos nem sequer foram traduzidos do russo.

Os estudos de Vigotski sobre a esquizofrenia, por exemplo, são pouco mencionados nas pesquisas, considerando as contribuições que podem oferecer na atualidade. Este artigo, portanto, visa apresentar a discussão que Vigotski traz para se pensar o processo de desagregação das funções psíquicas que acontece na esquizofrenia. Além disso, procuraremos demonstrar a atualidade de seus estudos ou achados, realizados no início do século XX, mas que podem ser referendados hoje por pesquisas que descrevem as alterações patológicas neste caso clínico, mesmo por autores que não se baseiam na Psicologia Histórico-Cultural.

Iniciaremos a discussão com a apresentação do processo de formação de conceitos no curso normal do desenvolvimento, ainda que de modo breve, para, em seguida, apresentar a tese central de Vigotski no que se refere à esquizofrenia: a existência de uma ruptura da função retora de formação de conceitos, na idade de transição. Por fim, traçaremos correlações entre as análises de Vigotski e o que algumas pesquisas atuais apresentam sobre o pensamento do indivíduo com esquizofrenia, buscando algumas problematizações.

\section{A FORMAÇÃO DE CONCEITOS CIENTÍFICOS COMO UNIDADE SUPERIOR}

\section{DAS FUNÇÕES PSÍQUICAS NA IDADE DE TRANSIÇÃO}

Para Vigotski (2000a, 2000b, 2000c), o psiquismo humano se constitui no curso normal do desenvolvimento como uma unidade de funções psíquicas que avançam de um funcionamento biológico ou primitivo para culturalmente formado ou superior. Deste modo, todas as funções que a criança possui ao nascer em estado simples ou reflexo (sensação, percepção, memória, atenção, pensamento, linguagem, volição etc.) ganham gradativamente um funcionamento mais complexo, qualitativamente diferente, culturalmente formado pelas mediações exercidas no interior das relações sociais.

O curso deste desenvolvimento, que para o autor é eminentemente dialético, ganha contornos distintos em conformidade com as relações criança/realidade social. Assim, as particularidades do seu meio social, ou a situação social de desenvolvimento, impactam o desenvolvimento da criança e criam uma nova criança, com novas habilidades desenvolvidas. Por sua vez, esta agirá de modo ativo em seu ambiente social, forçando igualmente mudanças nas relações ou na situação social de desenvolvimento, a qual necessariamente deve se alterar para atender às suas necessidades. Para Vigotski (1996b), são estes embates que produzem as crises ao longo do desenvolvimento infantil, as quais são superadas com a transformação da situação social de desenvolvimento original, que colocará novas tarefas à criança devido aos ganhos de desenvolvimento por ela alcançados. A não mudança na situação social de desenvolvimento poderá agravar e intensificar a crise, por exemplo, não proporcionando a superação desta para um novo período de estabilidade no desenvolvimento infantil.

A esquizofrenia, para Vigotski (1996a), é a ruptura e crescente desintegração da unidade complexa das funções psíquicas que se forma na idade de transição ou adolescência: a função de formação dos conceitos lógicos, abstratos e científicos. Assim, o curso normal pode explicar o patológico e o patológico, dialeticamente, explicaria o curso normal do desenvolvimento.

(...) os conceitos psicologicamente concebidos evoluem como significados das palavras. A essência do seu desenvolvimento é, em primeiro lugar, a transição de uma estrutura de generalização a outra. Em qualquer idade, um conceito expresso por uma palavra representa uma generalização. Mas os significados das palavras evoluem. Quando uma palavra nova, ligada a um determinado significado, é apreendida pela criança, o seu desenvolvimento está apenas começando; no início ela é uma generalização do tipo mais elementar, que à medida que a criança se desenvolve, é substituída por generalizações de um tipo cada vez mais elevado, culminando o processo na formação dos verdadeiros conceitos. (Vigotski, 2001, p. 246, grifos nossos)

Para compreendermos o processo de desagregação que se dá na esquizofrenia, é necessário antes que compreendamos como se constitui o desenvolvimento dos conceitos, desde a infância até a adolescência. Para Vigotski (2001), o significado da palavra é a unidade de análise da consciência, por ser a unidade que se constitui entre pensamento e linguagem. Em analogia aos instrumentos de trabalho que alteram a natureza externamente, Vigotski (2000a, 2000b, 2000c) atribui ao signo - ou às diversas formas de linguagem simbólica criadas pelos seres humanos - a função de instrumento psicológico, cujo papel é mudar internamente a natureza de nossas funções psíquicas de imediatas para mediadas. É o funcionamento mediado da percepção, da 
memória, da atenção, enfim, das funções psíquicas, que as caracterizam como superiores, em contraposição às elementares, que são imediatas.

Atendo-se ao desenvolvimento da linguagem simbólica oral, Vigotski (2001) explica que os significados das palavras não são imutáveis. Ao contrário, os significados passam por uma evolução por meio das relações sociais. É nas relações prático-verbais com os adultos que as crianças aprofundam os nexos com o real, criando novos enlaces conceituais por detrás das palavras. Vigotski (2001) apresenta fases do desenvolvimento do significado das palavras, as quais não estão presas a idades cronológicas e sim ao domínio crescente dos conceitos por detrás das palavras: sincretismo, complexos e conceito. Embora haja um predomínio do sincretismo na primeira infância e dos complexos até a segunda infância, ainda no adulto, diante de palavras desconhecidas ou que se refiram a um arcabouço teórico por ele desconhecido, seu pensamento pode operar por sincretismo ou complexo.

No sincretismo há a predominância da percepção e da sensação subjetiva frente ao som da palavra e, deste modo, uma palavra pode ser tomada como um xingamento, como um elogio, como algo bonito ou feio, degradante, pelo que o som desta produz na criança. Assim, o modo como a palavra afeta subjetivamente a criança dará o contorno de sua utilização. Neste momento, a criança não está voltada aos nexos objetivos, ou seja, à relação referencial da palavra, e sim aos nexos subjetivos. De acordo com Vigotski (2001), “(...) em vez do 'nexo desconexo' que serve de base à imagem sincrética, a criança começa a unificar objetos homogêneos em um grupo comum, a complexificá-los já segundo as leis dos vínculos objetivos que ela descobre em tais objetos" (p. 179).

O autor explica que devido às dificuldades que o emprego das palavras tomado a partir das sensações e percepções subjetivas ocasiona na esfera de suas comunicações e devido às atitudes de estranhamento dos adultos em relação aos usos inusitados que dará a determinadas palavras, a criança se voltará a observar a relação externa existente entre as palavras e os objetos da realidade, inaugurando a fase dos complexos. Para Vigotski (2001), nos diversos tipos de complexos, a criança está buscando captar a relação existente entre as palavras e os objetos, entre as palavras e as ações, enfim, volta-se aos nexos objetivos, porém ainda não consegue captá-los integralmente. Esse é o caráter parcial ou rudimentar desta captação que caracteriza todos os tipos de complexos: associativo, coleção, em cadeia, difuso e pseudoconceito. Na formação de complexos "o pensamento da criança complexifica, objetos particulares que ela percebe, combina-os em determinados grupos e, assim, lança os primeiros fundamentos de impressões dispersas, dá os primeiros passos no sentido da generalização dos elementos dispersos da experiência" (Vigotski, 2001, pp. 219-220, grifos nossos).
A fase de transição entre os complexos e os conceitos é denominada por Vigotski (2001) como pseudoconceito. Justamente porque a criança não cria sua linguagem, mas assimila a linguagem já desenvolvida pelas gerações anteriores, há um longo percurso de sua apropriação, desde o sincretismo até os complexos. Assim, conforme a criança valida ou não suas hipóteses em relação ao significado que confere às palavras, alcançará a etapa dos pseudoconceitos. De modo geral, a criança passa a fazer uso de um rol de palavras dentro das situações adequadas, porém apenas funcionalmente, repetindo muitas vezes explicações dadas pelos adultos. Isso ocorre porque ela tem o domínio prático do uso das palavras, mas ainda não as compreende em sua essência, sendo-lhe difícil explicar os significados sem recorrer a exemplos de situações concretas ou utilizando suas próprias palavras, e não as utilizadas pelos adultos quando lhe definiram o significado. Para Vigotski (2001), o pseudoconceito possui uma natureza funcional, sendo a transição ou elo entre o pensamento por complexos e o pensamento por conceitos, ou seja, a criança vai utilizando, aplicando as palavras na prática comunicativa com os adultos antes mesmo de assimilar ou internalizar os significados de modo mais sistematizado.

Como já exposto, mesmo os adultos escolarizados, embora operem mais com conceitos frente a palavras desconhecidas ou que não fazem parte da área de conhecimento que envolve o seu trabalho, por exemplo, podem operar com complexos ou pseudoconceitos. Por exemplo, a maioria das pessoas usuárias de tecnologias complexas atualmente emprega palavras como internet, rede, chip, entre outras, referindo-se externamente a práticas ou determinados dispositivos sem o domínio do conceito propriamente dito destas palavras.

Considerando o quadro acima, é necessário que se esclareça o salto qualitativo entre a formação de complexos e a formação de conceitos, em termos do pensamento. Além disso, é importante demarcar que o conceito vincula o pensamento à realidade, pois esta é seu referente, porém, ele abstrai sua essência para poder operar com esta de modo mais complexo. Nos conceitos mais cotidianos, como os de prato e pires, xicara e caneca, cadeira, banco e banqueta, pode-se verificar em seu núcleo uma operação de pensamento complexa que está por detrás, oferecendo condições para que uma criança possa selecioná-los, generalizando e ao mesmo tempo discriminando quais objetos entram em tais categorias. Como vimos, este processo é longo e dependente das relações prático-verbais com os adultos no interior da situação social de desenvolvimento de cada período em que a criança se encontra.

Novamente, Vigotski (2001) nos explica que é a relação prático-verbal da criança com o adulto que possibilitará a ela a transição para os conceitos. O conceito, mesmo o espontâneo, deriva da possibilidade de operar com processos de discriminação e generalização, 
simultaneamente. Enquanto nos complexos a criança capta um nexo e generaliza, fazendo com que objetos diferentes sejam inseridos ou incorporados em uma mesma palavra, no conceito é necessário que se generalize por meio da discriminação dos atributos essenciais do objeto e sua função social, o que delimita a generalização.

Mas o conceito, em sua forma natural desenvolvida, pressupõe não só a combinação e a generalização de determinados elementos concretos da experiência, mas também a discriminação, a abstração e o isolamento de determinados elementos e, ainda, a habilidade de examinar esses elementos discriminados e abstraidos fora do vínculo concreto e fatual em que são dados na experiência. (Vigotski, 2001, p. 220, grifos nossos)

No caso dos conceitos científicos, as operações de generalização e discriminação simultâneas ganham um grau de complexidade ainda maior, uma vez que os conceitos científicos integram sistemas conceituais e não podem ser tomados de modo isolado.

Do exposto até o momento, buscou-se elucidar a complexidade das relações com a realidade, expressa pelo desenvolvimento do significado das palavras, ao longo do desenvolvimento humano. Cada etapa deste desenvolvimento dá condições ao sujeito de apreender de modo mais profundo a essência dos fenômenos da realidade, que são descritos e explicados por meio de palavras. Podemos dizer que a compreensão da realidade por meio da linguagem simbólica nos liga e afasta ao mesmo tempo da mesma. Nos liga, pois podemos efetivamente compreender os nexos causais do real e explicá-los, nos afasta porque o fazemos de modo abstrato, cada vez mais desligado da experiência imediata, concreto-visual. É justamente este fio que parece romper-se no caso da esquizofrenia, como veremos a seguir.

\section{A RUPTURA DA UNIDADE DO REAL NO PSIQUISMO}

\section{DO ESQUIZOFRÊNICO:A FORMAÇÃO DE CONCEITOS}

Para Vigotski (1996a), a história do desenvolvimento das funções psicológicas superiores não é a história do desenvolvimento de um conjunto de mudanças isoladas de cada função. Deste modo, a evolução da vida intelectual do adolescente vem a ser um quadro integral único em que todas as partes estão vinculadas à sua conexão com o centro. O centro único ou a neoformação deste período é a função da formação de conceitos, que agrega todas as mudanças periféricas na psicologia do adolescente.

A atenção voluntária e a memória lógica, devido à formação de conceitos vão se intelectualizar e passam a ser regidas pelo pensamento em conceitos. Por um lado, tornam-se lógicas e, por outro, livres e independentes em relação às leis elementares que as subjazem, passando a ser dirigidas livremente por um pensamento consciente, voluntário. A percepção também sofre uma mudança radical, pois o pensamento por conceitos exige discernir e entender as próprias percepções, o que produz uma mudança na própria função perceptiva, que se subordina aos conceitos, os quais sintetizam o concreto e o geral que é percebido, ou seja, a própria realidade (Vigotski,1996a).

Por isso, para Vigotski (1996a), os dados patológicos sobre a desintegração e destruição desta complexa unidade funcional, auxiliam no entendimento da interdependência das funções da linguagem com outras do córtex cerebral. Estas funções que funcionam de modo unificado, em estados patológicos do sistema nervoso central passam a atuar de modo isolado, conforme a patologia.
Vemos, portanto, que o cérebro conserva em si, de forma espacial, uma sequencia documentada, temporal, de como vai desenvolver-se a conduta do indivíduo, enquanto que a desagregação de funções complexas, unitárias, nos permite aprofundar na história de seu desenvolvimento. (...) $O$ desenvolvimento é a chave para entender os processos patológicos, os processos de dissociação das sínteses, das unidades superiores e a patologia é a chave para entender a história do desenvolvimento e estruturação dessas funções sintéticas superiores. (Vigotski, 1996a, pp. 167-168, grifos nossos)

Vigotski (1996a) destaca que, em diversas patologias, a instância subordinada se faz independente e, ao analisá-la, podemos compreender os elementos que conserva de seu antigo funcionamento, mais primitivo. A emancipação dos centros inferiores é análoga à emancipação das funções inferiores ou elementares, que antes estavam incorporadas em uma síntese complexa, mas que ao se fragmentarem e desagregarem passam a atuar conforme leis primitivas. Para ele três enfermidades merecem estudos aprofundados nessa direção: a histeria, a afasia e a esquizofrenia. Nelas, é possível verificar, sob diversos aspectos, o movimento inverso do processo de desenvolvimento comum.

De acordo com Vigotski (1996a) a psiquiatria tradicional focalizava seus estudos nas vivências, nas modificações da consciência da realidade e na autoconsciência da personalidade do indivíduo com esquizofrenia, concentrandose nos conteúdos e ignorando as mudanças na forma. Por outro lado, estudava-se a esquizofrenia como um grau a mais em relação às perturbações que se davam no comportamento 
excêntrico do adolescente e por isso, por muito tempo, a esquizofrenia foi considerada demência precoce ou juvenil. Para o autor, embora existissem similaridades externas no comportamento adolescente e no patológico, é necessário analisar a essência do processo ou a natureza do fenômeno estudado, ou seja, avançar da descrição para a análise genética e funcional.

A possibilidade de aproximar a análise morfológica e funcional do pensamento dos esquizofrênicos, o passo do estudo do conteúdo de seu pensamento ao estudo de suas formas no brinda no caso dado, como em todos os demais, ao ponto de vista histórico, o método de análise genético que põe de manifesto a unidade e o recíproco condicionamento no desenvolvimento das formas e do conteúdo do pensamento. Esse método permite-nos descobrir na esquizofrenia o mesmo que temos visto na histeria e na afasia, ou seja, o descenso a um nível genético mais primitivo do desenvolvimento, a regressão, o passo atrás, o movimento inverso dos processos de desenvolvimento. (Vigotski, 1996a, p. 186, grifos nossos)

Para Vigotski (1996a), “(...) a patologia é a chave para entender o desenvolvimento e o desenvolvimento a chave para entender a patologia" (p. 187). Enquanto a psiquiatria tradicional se ocupava em descrever as mudanças produzidas na consciência e personalidade, neste enfoque devemos compreender as mudanças nos conteúdos em unidade com as alterações das formas do pensamento, pois estas se alteram tão radicalmente como os primeiros.

Romper com o enfoque unilateral do fenômeno é o que requisita Vigotski (1996a) ao postular que “(...) a formação de conceitos, justamente a função cujo desenvolvimento constitui o conteúdo principal do desenvolvimento intelectual na idade de transição, é afetada em grande medida na esquizofrenia" (p. 188). O caráter visual-direto aproxima o pensamento primitivo e o patológico, pois o pensamento do indivíduo com esquizofrenia não obedece mais a sistemas conceituais lógicos, mas vincula-se às suas impressões afetivas, perceptivas e imagéticas. Sendo assim, basta um aspecto comum que lhe impressione imediatamente para unificar ideias heterogêneas, pois a consciência de vínculos ou enlaces significativos passa para um plano secundário. O mundo do indivíduo com esquizofrenia, para Vigotski (1996a), não pode ser considerado um mundo caótico, amorfo, de ideias delirantes, desordenadas, carentes de sentido ou estrutura, mas se deve entendê-lo como um passo lógico para trás, um descenso a um nível inferior e mais primitivo do pensamento.

$\mathrm{Na}$ esquizofrenia se desintegram as unidades superiores ou os conceitos, se emancipa o pensamento em complexo, que como uma infraestrutura sempre está contida dentro dos conceitos, e as conexões complexas começam a dirigir o pensamento. Pois bem, como no homem normal toda a consciência da realidade e toda a consciência da própria personalidade está representada no sistema de conceitos, é natural que ao decompor-se e dissociar-se estes últimos, se destrua também todo o sistema de consciência da realidade e todo o sistema da consciência da personalidade. As mudanças no conteúdo do pensamento são o resultado direto da desintegração das funções do pensamento. (Vigotski, 1996a, p. 189, grifos nossos)

O ponto que Vigotski (1996a) destaca é o fato de que, se é a consciência que nos orienta na realidade e a base da consciência está ancorada no sistema de conceitos, sendo este o sistema de referência que nos orienta no mundo, a desintegração deste produz a desorientação do sujeito em relação ao mundo que o rodeia, em relação às pessoas e a si mesmo.

Temos repetido muitas vezes que nem todo conteúdo pode incluir-se em qualquer forma. O conteúdo não é indiferente ante a forma do pensamento, não a preenche de modo puramente externo mecânico como completa o líquido um recipiente. Estudando o desenvolvimento da função de formação de conceitos temos visto que o passo a um nível superior, o domínio de uma nova forma do pensamento brinda o adolescente a possibilidade de conhecer novas áreas no conteúdo do pensamento. Essas novas áreas se fecham para o esquizofrênico e o conteúdo de sua consciência volta ao sistema primitivo de conexões complexas que correspondem a esse tipo de pensamento, conexões que vão parecer confusas à consciência acostumada ao pensamento em conceitos. $A$ confusão se deve a que tal regressão, nomeadamente, o passo ao pensamento em complexos jamais pode ser completo. (Vigotski, 1996a, p. 189, grifos nossos)

Vigotski (1996a) explica que, em função disso, o indivíduo com esquizofrenia vive um mundo ambivalente, por um lado repleto de imagens visual-diretas, ricas de mágicas conexões e, por outro lado, há momentos que consegue discernir e estranhar tais formas de pensamento. Deste modo pode tomar como realidade as vivências primitivas ou ter consciência de que são ilusórias, como uma confusão e mescla de associações novas e aparentemente sem nexo e as velhas, ancoradas nos fragmentos do modo de pensamento anterior (conceitual). Vigotski (1996a) expõe que os próprios relatos dos enfermos confirmam a tese, como a história de um jovem de 24 anos que se lamentava dizendo que suas ideias eram dispersas e tudo lhe parecia instável e impreciso. Seus pensamentos se confundiam impregnados de sentimentos em que tudo se juntava, uma coisa se transformava em outra como se estivesse sonhando. "Os momentos perceptivos de diversos elementos e os momentos emocionais se fundem e constituem uma espécie de amálgama psíquico" (Vigotski, 1996a, p. 190).

Unicamente se admite a existência de uma lesão primária na própria função encarregada de formar os conceitos, a que se segue a desintegração da complexa síntese que aparece relativamente tarde na história do desenvolvimento (a separação e emancipação de mecanismos mais antigos contidos nela), o quadro adquire sentido e claridade. Temos visto que 
os conceitos se formam quando foram desenvolvidas todas as funções psíquicas superiores, que a função de formação de conceitos não se desenvolve ao lado das demais funções, que está sobre elas, representando sua peculiar e complexa combinação. (Vigotski, 1996a, p. 193)

Por isso que, na esquizofrenia, ao desagregar-se a formação de conceitos: “A percepção em conceitos, o mesmo que a memória em conceitos se dissocia e é substituída por formas mais primitivas e iniciais da percepção e da memória" (Vigotski, 1996a, p. 193, grifos nossos). Deste modo, não se modifica somente o conteúdo de alguns conceitos ou algumas conexões, mas toda a percepção da realidade fica alterada, todas as vivências do mundo circundante, pois o quadro do mundo perde sua sistematização, organização e se destrói. Juntamente com a desintegração do mundo ocorre a desintegração do "eu" ou da personalidade em diversos componente parciais, que não se agrupam em um todo global, além da perda da linha divisória entre o "eu" e o mundo circundante. "O quadro coerente do mundo e da autoconsciência da personalidade se dissociam quando se perde a função de formação de conceitos" (Vigotski, 1996a, p. 196, grifos nossos).
Experimenta-se a vivência de um mundo ambíguo, por um lado repleto de imagens visuais-diretas, participações mágicas ou fantasmagóricas e, por outro, o do pensamento anterior, parcialmente conservado e em concordância com a sua experiência e a realidade. No entanto, o pensamento por conceitos deixa de ser predominante e esta dissociação e ambiguidade atinge diversas esferas da conduta, como por exemplo, a atividade volitiva que apresentará uma insuficiência das funções intencionais, a falta de unificação das tendências ou impulsos a um sistema relativamente sólido que coordene a ação. Deste modo, o quadro patológico pode se apresentar como uma pobreza de impulsos e de reações ante a realidade, como por uma exacerbação de atuações na realidade circundante, sem mecanismos de autocontrole ou autoplanejamento. Como veremos a seguir, tais características do comportamento do indivíduo com esquizofrenia ainda são consensuais entre os pesquisadores, sendo descritas na maioria das pesquisas e sendo parte da sintomatologia descrita no DSM-V. No entanto, como veremos, a maioria das pesquisas carecem de explicações sobre as causas de tais sintomas e quando o fazem situam-se em explicações reducionistas de cunho biológico.

\section{DOS ESTUDOS DE VIGOTSKI SOBRE ESQUIZOFRENIA AOS ATUAIS}

Até o momento, procuramos demonstrar que a neoformação da idade de transição é a formação de conceitos lógicos, que intelectualiza todas as demais funções psíquicas e as une numa síntese superior. De acordo com Vigotski (1996a), nos estados patológicos, as funções que antes operavam de modo integrado passam a atuar de modo isolado conforme a patologia.

Como vimos, para Vigotski (1996a) a psiquiatria tradicional focalizava seus estudos nas vivências, nas modificações da consciência da realidade e na autoconsciência da personalidade do indivíduo com esquizofrenia, concentrando-se nos conteúdos e ignorando as mudanças na forma. Por isso, para ele, era fundamental avançar da descrição para a análise genética e funcional, para a compreensão do estado patológico em sua essência. $\mathrm{O}$ autor indica que uma linha de análise é a de que o caráter visualdireto aproxima o pensamento primitivo e o patológico, pois o pensamento passa a não obedecer mais a sistemas conceituais lógicos, vinculando-se às suas impressões afetivas, perceptivas imagéticas e auditivas.

A desintegração da função de formação de conceitos é a explicação do caos que se apresenta no discurso e no pensamento do indivíduo com esquizofrenia, mas essa desintegração não ocorre de uma vez. Para Vigotski (1996a) o modo como se apresentam estes momentos de integração/desintegração tem direta relação com a condição de desenvolvimento cultural pregressa do sujeito, ou seja, seu nível de escolarização e formação, classe social, acesso e domínio da linguagem simbólica mais elaborada (leitura, escrita matemática), fatores que condicionam o desenvolvimento do pensamento teórico, dos conceitos científicos. Este fato muitas vezes é ignorado nos estudos referentes a esquizofrenia.

Vejamos agora uma síntese de algumas investigações atuais a respeito da esquizofrenia. Antes, iniciaremos por uma breve descrição do que consta no polêmico Manual Diagnóstico e Estatístico de Transtornos Mentais ou DSM-V (American Psychiatric Association [APA], 2014). Nele, a esquizofrenia é integrante dos Transtornos do Espectro da Esquizofrenia e Outros Transtornos Psicóticos. A avaliação realiza-se mediante a ausência/presença de cinco sintomas críticos: (a) delírios; (b) alucinações; (c) discurso desorganizado; (d) comportamento extremamente desorganizado ou catatônico, e (e) sintomas negativos (que se referem à expressão emocional diminuída, avolia ou redução de atividades motivadas, alogia ou diminuição do discurso, anedonia ou capacidade reduzida de sentir prazer e falta de sociabilidade). Quando dois sintomas acima se apresentam, sendo um deles necessariamente a, b ou c, em conformidade com a APA (2014), associados a um funcionamento profissional ou social prejudicado, pode-se pensar no diagnóstico de Esquizofrenia.

Conforme a APA (2014), os sintomas prodrômicos aparecem antes da fase ativa e o indivíduo manifesta crenças incomuns ou estranhas, porém ainda não delirantes (p. ex., ideias de referência ou pensamento mágico), experiências perceptivas raras (p. ex., sentir a presença de uma pessoa invisível), discurso vago e comportamento incomum, 
mas não grosseiramente desorganizado (p. ex., murmurar em público). "Indivíduos que eram socialmente ativos podem ficar retraídos em relação a rotinas anteriores. Esses comportamentos são frequentemente o primeiro sinal de um transtorno" (APA, 2014, p.101). O Manual apresenta como prevalência 0,3 a $0,7 \%$, sendo que os primeiros sintomas costumam aparecer no final da adolescência até por volta de 30 anos, sendo raros os casos antes deste período.

Como fatores de risco e prognóstico são destacados fatores ambientais e genéticos ou fisiológicos. Dentre os primeiros, por incrível que pareça, inclui-se a estação do ano em que o indivíduo nasceu. Vejamos na íntegra:

A estação do ano no nascimento é associada à incidência da esquizofrenia, incluindo fim do inverno/início da primavera em alguns locais e verão para a forma da doença com déficits. A incidência de esquizofrenia e transtornos relacionados é mais alta em crianças que crescem em ambiente urbano e em alguns grupos étnicos minoritários. (APA, 2014, p. 103)

O exposto acima não é explicado no manual e nem referenciadas pesquisas que possam ratificar tais afirmações. Com relação aos fatores genéticos e fisiológicos, são muitas as contradições, devido à sua imprecisão, amplitude e à correlação dos mesmos com diversas outras patologias:

Existe forte contribuição dos fatores genéticos na determinação do risco para esquizofrenia, embora a maioria dos indivíduos com diagnóstico do transtorno não tenha história familiar de psicose. Essa tendência é atribuida a um espectro de alelos de risco, comuns e raros, com cada um contribuindo somente com uma pequena parcela para a variância total da população. $O s$ alelos de risco identificados até agora são também associados a outros transtornos mentais, incluindo transtorno bipolar, depressão e transtorno do espectro autista.

Complicações na gestação e no nascimento, com hipoxia, e idade avançada dos pais estão associadas a maior risco de esquizofrenia para o feto. Além disso, outras adversidades no pré-natal e no perinatal, incluindo estresse, infecções, desnutrição, diabetes materno e outras condições médicas, têm ligação com a esquizofrenia. A grande maioria dos bebês com esses fatores de risco, entretanto, não desenvolve a doença. (APA, 2014, p.103, grifos nossos)

O exposto é corroborado pelos estudos de Tengan e Maia (2004) e por Silva et al. (2016a, 2016b) no que se refere à definição, sintomas, aos prejuízos, à prevalência e idade de início, ou seja, é considerada uma patologia rara na infância, confirmando as discussões de Vigotski (1996a). Porém, de acordo com Tengan e Maia (2004), apesar do debate existente a respeito das causas da esquizofrenia circunscrever-se entre as explicações organicistas e as psicodinâmicas, defendem que nos últimos anos se comprovou a causa genética do transtorno, ou seja,
(...) o padrão de herança familiar genético é que foi comprovado, pois, enquanto não se localizar com precisão qual cromossomo e qual(is) gene(s) está(ão) envolvido(s), ainda se estará investigando a causa propriamente dita. $O$ que se pode afirmar é que a causa NÃO é psicológica, mesmo se a evolução, a patoplastia e a apresentação do quadro são únicas, estas sim sendo causadas pelo ambiente psicológico. (Tengan \& Maia, 2004, p. 5, grifos nossos)

Tal como na citação acima, observamos que, mesmo no DSM-V (2014), as causas da esquizofrenia e os fatores de risco se apresentam de maneira genérica e difusa e não por acaso tem recebido inúmeras críticas por seu reducionismo. Por exemplo, Caponi (2014) analisa, pautando-se nos estudos de Foucault, as críticas aos DSM-V realizadas por Thomas Insel, diretor do National Institute of Mental Health (NIMH) e Allen Frances, chefe do grupo que elaborou o DSM-IV. Para Caponi (2014):

O DSM-V se inscreve na mesma estratégia que caracteriza os Manuais de Estatística e Diagnóstico de Transtornos Mentais desde sua ruptura operada no campo da psiquiatria, no ano de 1980, pelo DSM-III. A partir deste momento, começou-se a definir as patologias psiquiátricas por agrupamentos de sintomas, o que acarretou a desconsideração das narrativas dos pacientes, das histórias de vida, das causas sociais e psicológicas especificas que podem ter provocado determinado sofrimento psíquico ou determinado comportamento. (p.744, grifos nossos)

Segundo Caponi (2014), numa análise mais aprofundada, a crítica de Insel se pauta nos postulados localizacionistas e biologizantes cuja origem data de $1830 \mathrm{com}$ os estudos de Gall (Frenologia). Ou seja, para a autora, ele apenas instiga à necessidade de se buscar os marcadores biológicos necessários para o diagnóstico (localização cerebral ou processos neuroquímicos) possíveis de identificação em exames ou por marcadores genéticos. O problema do DSM-V estaria na falta de validação dos sintomas e a sua defesa é pelo estabelecimento de bases neurológicas para as classificações psiquiátricas.

Por outro lado, a crítica de Frances, de acordo com Caponi (2014) considera a lista de patologias do DSM-V mal formulada, obscura e inconsistente, resultando em um acréscimo de patologias:

O incremento das taxas de transtornos mentais na população ocorre, sustenta Frances, de dois modos: 1) pela criação de novos diagnósticos que transformam em patológicos comportamentos comuns na sociedade, que a indústria farmacêutica se encarregará de popularizar (como a tristeza, os pequenos déficits de cognição, as explosões de raiva, os comportamentos sexuais, as adições a certas condutas cotidianas como comprar, o uso de substâncias tóxicas, etc.); 2) estabelecendo um limiar de diagnóstico mais baixo para muitas patologias existentes, como de fato ocorreu ao retirar a excepcionalidade concedida a casos de luto para o diagnóstico 
de depressão. (Frances citado por Caponi, 2014, p. 252, grifos nossos)

Na mesma direção crítica, Jardim (2016) traz uma discussão interessante a partir da psicanálise, a respeito do mal-estar no campo da psicopatologia contemporânea, propondo uma posição clínica, ética e epistemológica na abordagem do sofrimento psíquico, sem recair no reducionismo organicista ou defender um puro psicologismo dos transtornos mentais. Resgata as críticas feitas por Thomas Insel ao DSM-V da seguinte forma:

O DSM-V é uma ferramenta pragmática e eficaz para localizar o enfermo em uma classificação, inclusive quando - e isso ocorre com alguma frequência - outro clínico ou o mesmo em outro momento eleja outra divisão do manual para o paciente. Nesta medida, a tarefa terapêutica pode ser simplificada, pois quando se alcança saber a qual classificação do manual corresponde o paciente, se pode eleger o tratamento correspondente, tanto o psicoterapêutico como o farmacológico. É indubitável que o sistema classificatório do DSM-V também é um auxiliar excelente para a tarefa estatística. Por último, e não menos importante, o médico detém o conhecimento acerca do transtorno e a solução do problema. Na psiquiatria clínica contemporânea é invariavelmente a psicofarmacologia que tem dominado a prática ao longo das últimas décadas. (Jardim, 2016, p.327, tradução nossa)

Segundo Jardim (2016), a concepção naturalista que dá base às classificações do DSM-V produz um empobrecimento da clínica em psicopatologia, criando um mal-estar no que se refere às propostas terapêuticas para os indivíduos adoecidos, pelo reducionismo ao empirismo do comportamento. Para a autora, não se pode transformar a psicopatologia em um puro campo de expressão biológica, utilizando-se de "poções mágicas" para manter bons níveis de serotonina, noradrenalina e dopamina, o que em um ponto realista significa uma imobilidade diante de interesses econômicos, principalmente da indústria farmacêutica que transforma o psiquiatra em um mero distribuidor de psicofármacos. E segue com suas reflexões, com as quais concordamos, embora a partir de um referencial teórico diferente da autora:

Sem dúvida, uma coisa é tomar um remédio com a esperança de que possa eliminar um sintoma ou curar uma enfermidade, outra é esperar que isso constitua um sujeito. Pois, ele somente se constitui enquanto um ser em falta e separado de qualquer objeto, e nenhum fármaco, por mais poderoso que seja, vai reincorporar a perda para ele. (Jardim, 2016, p.329-30, tradução nossa)

Do exposto, observamos que críticas atuais ao modo hegemônico pelo qual a Psiquiatria vem compreendendo, descrevendo e tratando as patologias mentais aproximamse das críticas de Vigotski (1996a). Por isso, entendemos e afirmamos a importância dos estudos referentes a tais patologias da vida mental avançar na elaboração de um corpus teórico que vá além da descrição sintomática. Verifica-se a urgência em superar a descrição de sintomas pela busca por princípios explicativos que compreendam o desenvolvimento do psiquismo normal e patológico como uma unidade complexa de aspectos biológicos e sociais. Somente assim não haverá estranhamento em relação ao fato de que determinadas formas patológicas diminuam e outras aumentem em determinado momento histórico, conforme determinadas formas de organização social. É necessário compreender a relação indivíduo/sociedade, na qual os aspectos sãos e patogênicos não podem ser delimitados em um único polo da mesma. Essa problemática foi destacada por Vigotski (1996a) e parece ainda não ser central nas discussões atuais.

Seguindo com a breve explanação sobre os estudos atuais sobre a esquizofrenia, a revisão da literatura realizada por Ferreira Junior, Barbosa, Barbosa, Hara e Rocha (2010) a respeito das alterações cognitivas na esquizofrenia, em artigos publicados entre 2004 e 2009, apresenta considerações importantes, tais como: (1) as pesquisas possuem grande diversidade de métodos utilizados, o que prejudica a interpretação e comparação dos resultados dos diversos estudos; (2) poucas pesquisas que permitem a comparação de resultados demonstram que o indivíduo esquizofrênico tem alterações na cognição social e este é o fator responsável pelo isolamento social do paciente, presente desde o primeiro episódio psicótico; (3) nos estudos indica-se, além do tratamento psicofarmacológico, tratamentos psicossociais para uma abordagem global do indivíduo com esquizofrenia.

Embora a revisão acima possa parecer desatualizada, dados coletados por Lima e Espíndola (2015) trazem resultados semelhantes numa revisão de literatura em artigos de 2003 a 2013, objetivando verificar quais as alterações nos processos cognitivos são destacadas nos estudos com indivíduos com esquizofrenia. Os estudos revisados apontam para as seguintes funções cognitivas mais comprometidas: velocidade de processamento, memória (operativa, verbal e visual), raciocínio e resolução de problemas, cognição social e atenção voluntária. De acordo com as autoras, as alterações são amplas e precisam ser consideradas no processo de avaliação e reabilitação, observando as funções preservadas e prejudicadas. Destacam que a reabilitação neuropsicológica visa restabelecer funções cerebrais e comportamentais objetivando promover a qualidade de vida, incorporando a noção de neuroplasticidade que compreende a condição do organismo modificar-se por meio de suas relações com o meio externo. É importante destacar que as autoras se baseiam na abordagem da Análise do Comportamento, cujos fundamentos epistemológicos são distintos da Psicologia Histórico-Cultural.

Ainda com relação aos prejuízos cognitivos apresentados por indivíduos com esquizofrenia, diversos estudos referemse aos que podem ser compreendidos como integrantes das 
Funções Executivas (FE). A pesquisa realizada por Uehara et al. (2013), embora controversa pelo fato de classificar os estudos de A.R. Luria nas abordagens cognitivista e neuropsicológica e L. S. Vigotski como pertencente à abordagem desenvolvimentista em conjunto com J. Piaget, do que discordamos ${ }^{1}$, tem seu mérito por apresentar a existência de inúmeros modelos explicativos, díspares em seus fundamentos epistemológicos, em torno do que se compreende como Funções Executivas (FE). Sua revisão de literatura abarca o período de 1990 a 2013, incluindo artigos, estudos experimentais e capítulos de livros, categorizando os achados e agrupando-os por aproximação teórica, permitindo a organização do material em quatro abordagens explicativas: cognitivista, neuropsicológica, psicométrica e desenvolvimentista. Para Uehara et al. (2013), o caráter complexo das FE originou diversos modelos de compreensão do funcionamento executivo disfuncional e pode auxiliar no diagnóstico das diversas habilidades nele envolvidas, incorporando diversas áreas como a neuropsicologia clínica, a psicopatologia, a psicologia do desenvolvimento e a educação. No entanto, embora existam diversos modelos explicativos, o conceito necessita de maior refinamento, segundo os autores, pois ainda não há consenso nas investigações.

Aqui vale um destaque, embora seja possível em uma análise rápida, aproximar os estudos de Vigotski, ou mesmo de Luria, aos realizados sobre as funções executivas na atualidade, entendemos ser temerosa esta aproximação sem uma pesquisa aprofundada que parta das bases epistemológicas das vertentes teóricas elencadas. Como este não é o objetivo deste artigo, apenas trazemos à baila esta preocupação para que futuras investigações sejam realizadas, considerando o sistema conceitual dos autores supracitados e a base teórica que sustenta os diversos modelos que discutem as Funções Executivas (FA).

Outra revisão, realizada por Zimmer et al. (2008), cujo objetivo foi sintetizar estudos sobre os testes neuropsicológicos que estão sendo mais empregados no diagnóstico das alterações cognitivas resultantes da esquizofrenia no período entre 1995 e 2006, evidenciou: (1) que há uma ampla heterogeneidade nos critérios de seleção dos testes neuropsicológicos, divergências na nomenclatura e certa tendência para a criação de novos testes e baterias para avaliação de funções cognitivas, aspecto também comprovado por Uehara et al. (2013) na discussão sobre a abordagem psicométrica; (2) que a relevância e características dos prejuízos cognitivos na esquizofrenia revelam a urgente necessidade de identificação específica e padronizada de métodos de avaliação neuropsicológica para

1 Discordamos da inclusão de A. R. Luria nestas categorizações, pois para fazê-lo é necessário desconsiderar a sua vinculação à Psicologia Histórico-Cultural, a qual foi elaborador juntamente com L. S. Vigotski. Tuleski (2010), em sua pesquisa demonstrou o quanto há apropriações indevidas dos estudos lurianos, quando se recorta uma única publicação do conjunto da obra do autor. pacientes brasileiros; (3) que dentre os testes mais utilizados encontram-se: Wisconsin Card Sorting Test (WCST) e Wechsler Adult Intelligence Scale (WAIS-III).

Zuanazzi e Larsen (2015) também realizaram uma revisão de literatura mais recente, objetivando investigar a produção brasileira sobre a temática do uso de instrumentos projetivos/expressivos na avaliação de indivíduos com esquizofrenia. As autoras apontam que para a avaliação das funções cognitivas os testes mais utilizados são os neuropsicológicos, como inventários, escalas e testes de desempenho/capacidade, com o objetivo de traçar um perfil cognitivo e afetivo do paciente. Para avaliação da personalidade também são utilizados inventários, questionários ou escalas. Tais instrumentos são considerados problemáticos em patologias graves como a esquizofrenia, uma vez que o indivíduo apresenta distorções da percepção da realidade e de si mesmo, sendo os instrumentos projetivos/ expressivos uma alternativa interessante para o processo avaliativo, de acordo com as autoras. Tais instrumentos avaliam tanto aspectos de personalidade quanto cognitivos de modo integrado e por isso apontam suas contribuições na avaliação de indivíduos com esquizofrenia, por serem menos diretivos, requisitarem menos instruções e pela facilidade de utilização em diversos contextos.

Com relação à problemática da avaliação em psicopatologia na atualidade, Caponi (2014) também oferece contribuições importantes para reflexão:

O que substitui a avaliação da significação clínica são as novas estratégias diagnósticas, com maior pretensão de objetividade, que incluem a aplicação de checklist, as valorações dimensionais para rasgos de personalidade, as pontuações de severidade - enfim, todo um arsenal quantitativo que já estava presente nas edições do DSM e que no DSM-V se intensifica. (p. 752-3, grifos nossos)

Caponi (2014) atenta ao fato de que muitos profissionais de saúde expõem que a eles é negada a condição de ouvir as narrativas dos pacientes, pelo pouco tempo que possuem para realizar as consultas, o que os limita ao registro dos sintomas. Porém, para a autora, em muitas patologias o conjunto de sintomas que leva ao diagnóstico é um "denominador comum" de situações de vida que podem ser fatais ao serem desconsideradas, tais como a violência familiar, o assédio moral no trabalho, assédio ou violência sexual, etc.

(...) independentemente da pluralidade dos contextos em que emergem os sofrimentos, dado um conjunto semelhante de sintomas (alteração de sono e apetite, sentimento de infelicidade ou culpa, tristeza profunda), todos os casos (ou a grande maioria) tenderão a receber um diagnóstico de depressão, um mesmo código burocrático e uma mesma (ou semelhante) medicação, como um ISRS (Inibidor Seletivo de Recaptação de Serotonina), independentemente das circunstâncias concretas de vida. (Caponi, 2014, p. 759, grifos nossos) 
Os estudos brevemente sintetizados, mesmo partindo de referenciais teóricos distintos, em diversos aspectos convergem com as críticas de Vigotski (1988) e Luria e Majovski (1977), sobre os testes padronizados que quantificam as respostas do sujeito, mas não as qualificam, procurando compreendê-las como expressão de um determinado sistema psíquico em desagregação, resultante de determinadas condições de vida. A maioria dos testes padronizados, muitos pautados no DSM-V como indicam Jardim (2016) e Caponi (2014), elimina a intervenção do examinador, retirando um aspecto central que seria a possibilidade de se compreender o processo e não somente o resultado. No caso específico da esquizofrenia, este fato é ainda mais problemático, uma vez que é consensual o prejuízo cognitivo, da linguagem e da organização do comportamento e as formas de avaliação que limitam a intervenção do examinador, limitam a possibilidade de se estabelecer se a modificação de determinadas condições, produziria modos diferenciados de reação nos sujeitos. Esta crítica já foi apontada por Vigotski (1988) de que os testes padronizados e escalas não analisam o nível potencial de desenvolvimento e por isso limitam as possibilidades de se planejar intervenções ao se concentrarem em descrever apenas o quadro atual, ou seja, o que o sujeito consegue responder ou realizar sozinho. Não queremos afirmar a inexistência de esforços por parte de profissionais voltados ao diagnóstico clínico, buscando uma visão mais ampla e integradora, incorporando diversas formas de avaliação (quantitativas e qualitativas) para compreensão dos quadros patológicos. No entanto, infelizmente ainda predomina a descrição sintomatológica e o modelo biomédico no processo avaliativo, tal como exposto por Zuanazzi e Larsen (2015), Ricci e Leal (2016), Jardim (2016) e Caponi (2014).

Por exemplo, a título de finalização da discussão, Ricci e Leal (2016) fizeram uma revisão bibliográfica narrativa sobre o cotidiano de indivíduos com o diagnóstico de esquizofrenia, publicados em forma de artigos em periódicos indexados, em 2014. Selecionaram 281 artigos nacionais e internacionais e destes, somente um terço (82 artigos) relatam/descrevem ou dão destaque às narrativas dos indivíduos com esquizofrenia e sua experiência com o adoecimento. Para as autoras, a luta se apresenta desigual entre os estudos baseados no modelo biomédico e os que propõem compreender a experiência de adoecimento dos indivíduos em suas particularidades. São majoritários os estudos que destacam variáveis como: etiologia, diagnóstico, prognóstico, tratamento, agudeza, cronicidade e curso da enfermidade mental. E, são minoritários os estudos que abarcam o contexto histórico-cultural em que a pessoa vive, seu modo de agir no mundo, suas relações com os demais e como compreende sua existência e seu próprio adoecimento.

Poderíamos nos estender aqui citando inúmeras investigações, porém de modo geral, observa-se que há uma tendência a biologização das causas da esquizofrenia e, quando não, as explicações se pautam na descrição dos sintomas, procurando detalhá-los, mas não explicam ou analisam os problemas apresentados na conduta, na linguagem, no pensamento, na memória, na percepção, na organização do comportamento, etc. Concluímos que a despeito do aumento dos estudos sobre a esquizofrenia na atualidade, ainda é possível evidenciar uma tendência à descrição e não explicação, que desconsidera a análise da unidade forma $\mathrm{X}$ conteúdo das alterações cognitivas apresentadas pelos pacientes esquizofrênicos. Neste sentido, mais de meio século se passou e a crítica de Vigotski (1996a) ainda é atual, impondo a necessidade de se avançar da descrição para a análise genética e funcional referente a esta patologia, no que se refere à constituição e desagregação das funções psíquicas nos quadros de esquizofrenia.

\section{SOBRE AS POSSIBILIDADES QUE SE ABREM...}

Até agora vimos que as críticas de Vigotski (1996) ainda se fazem atuais. Os estudos voltados às patologias mentais, no caso específico aqui, da esquizofrenia, ainda se limitam à descrição sintomática, a elaboração de baterias de testes que buscam, por meio de escores quantitativos, diagnosticar e estabelecer o prognóstico. No que diz respeito às explicações sobre o como e o porquê tais sintomas surgem, pouco se avançou para além do apontamento de causas orgânicas, muitas ainda não plenamente comprovadas. Evidencia-se claramente a predominância de teorias que se ancoram no que Leontiev (1978) determinou de teorias dos dois fatores. Ora se prioriza o organismo, ora o meio e, quando muito, se compreende o organismo com alguma deficiência somado a fatores ambientais, explicação típica que se baseia na lógica formal. Somente a superação da lógica formal pela lógica dialética, que opera com os contrários em unidade e não em oposição, possibilitará a compreensão de que há uma inter-relação recíproca entre os aspectos orgânicos e sociais, tanto na formação do psiquismo saudável quanto patológico.

Por outro lado, verificamos uma tentativa ainda tímida de superação desta dicotomia, ou seja, a busca de uma integração dos conhecimentos da área médica e psicológica, principalmente pautando-se nos aportes teóricos da Psicologia Histórico-Cultural. No âmbito da Psicologia temos os trabalhos já citados no início deste artigo, como, por exemplo, os de Martins (2002), Berenchtein Netto (2007), Silva (2009), Lima e Carvalho (2013), Almeida e Gomes (2014), Silva (2014), entre outros. 
Entendemos que esta tarefa está somente iniciada e requer uma conjugação de esforços por parte de pesquisadores das diversas áreas, para que possamos nos libertar das visões dicotômicas e reducionistas, meramente descritivas e quantitativas ainda predominantes, que pouco nos auxiliam na compreensão de um quadro tão complexo quanto o da esquizofrenia.

\section{REFERÊNCIAS}

American Psychiatric Association. (2014). Manual Diagnóstico e Estatístico de Transtornos Mentais ( $5^{\mathrm{a}}$ ed.). Porto Alegre: Artmed.

Almeida, M. R. de, \& Gomes, R. M. (2014). Medicalização social e educação: Contribuições da teoria da determinação social do processo saúde-doença. Nuances: Estudos sobre Educação, 25(1), 155-175.

Berenchtein Netto, N. (2007). Suicídio: Uma análise psicossocial a partir do materialismo histórico dialético (Dissertação de Mestrado). Pontifícia Universidade Católica, São Paulo, SP, Brasil.

Caponi, S. (2014). O DSM-V como dispositivo de segurança. Physis Revista de Saúde Coletiva, 24(3), 741-763.

Duarte, N. (2000). Vigotski e o "aprender a aprender": Críticas às apropriações neoliberais e pós-modernas da teoria vigotskiana. Campinas, SP: Autores Associados.

Ferreira Junior, B., Barbosa, M., Barbosa, I. G., Hara, C., \& Rocha, F. L. (2010). Alterações cognitivas na esquizofrenia: Atualização. Revista de Psiquiatria do Rio Grande do Sul, 32(2), 57-63.

Jardim, L. L. (2016). El malestar en la psicopatología contemporânea Psicologia USP, 27(2), 326-331.

Leontiev, A. N. (1978). Atividade, consciência e personalidade. Recuperado de http://www.marxists.org/portugues/ leontiev/1978/activ_person/index.htm

Lima, A. B. de, \& Espíndola, C. R. (2015). Esquizofrenia: Funções cognitivas, análise do comportamento e propostas de reabilitação. Revista Subjetividades, 15(1), 105-112.

Lima, P. M. de, \& Carvalho, C. F. de (2013). A Psicoterapia SócioHistórica. Psicologia: Ciência e Profissão, 33(n. especial), 154-163. Recuperado de http://www.scielo.br/scielo. php?script=sci_arttext\&pid=S1414-98932013000500015\&ln $\mathrm{g}=$ en\&nrm=iso

Luria, A. R., \& Majovski, L. V. (1977). Basic approaches used in American and Soviet clinical neuropsychology. American Psychologist, 32(11), 959-968.

Martins, S. T. F. (2002). Educação científica e atividade grupal na perspectiva sócio-histórica. Ciência \& Educação (Bauru), 8(2), 227-235, Recuperado de http://www.scielo.br/scielo. php?script=sci_arttext\&pid=S1516-73132002000200007\&ln $\mathrm{g}=\mathrm{pt} \& \mathrm{nrm}=$ iso.

Prestes, Z. R. (2010). Quando não é quase a mesma coisa: Análise das traduções de Lev Semionovitch Vigotski no Brasil. Repercussões no campo educacional (Tese de Doutorado). Universidade de Brasília, Brasília, DF, Brasil.

Ricci, E. C., \& Leal, E. M. (2016) Cotidiano, esquizofrenia e narrativas da experiência de adoecimento. Cadernos Brasileiros de Terapia Ocupacional, 24(2), 363-372.

Silva, A. M., Santos, C. A. dos, Miron, F. M., Miguel, N. P., Furtado, C. de C., \& Bellemo, A. I. S. (2016a). Esquizofrenia: Uma revisão bibliográfica. Revista UNILUS Ensino e Pesquisa, 13(30),18-25.
Silva, F. G. da (2009). Subjetividade, individualidade, personalidade e identidade: Concepções a partir da psicologia históricocultural. Psicologia da Educação, (28), 169-195. Recuperado de http://pepsic.bvsalud.org/scielo.php?script=sci arttext\&pid=S1414-69752009000100010\&lng=pt\&nrm=iso

Silva, J. L. R. da, Santos, L. M. de M., Lima, U. T. S. de, Santos, T. S. dos, Santos, K. da S., \& Barros, P. M. F. P. de. (2016b). Análise da produção científica sobre Esquizofrenia. Revista de Atenção à Saúde, 14(50), 70-78.

Silva, M. A. S. da (2014). Compreensão do adoecimento psíquico: De L. S. Vigotski à Patopsicologia de Bluma V. Zeigarnik (Dissertação de Mestrado). Universidade Estadual de Maringá, Maringá, PR, Brasil.

Tengan, S. K., \& Maia, A. K. (2004). Psicoses funcionais na infância e adolescência Jornal de Pediatria, 80(2), S3-S10.

Tuleski, S. C. (2010). As apropriações contemporâneas dos estudos de A. R. Luria e suas implicações para a psicologia e Educação. Revista Eletrônica Arma da Crítica, 2(Número Especial), 155-177.

Uehara, E., Charchat-Fichman, H., \& Landeira-Fernandez, J. (2013). Funções executivas: Um retrato integrativo dos principais modelos e teorias desse conceito. Revista Neuropsicologia Latinoamericana, 5(3), 25-37.

Vigotski, L. S. (2001). A construção do pensamento e da linguagem. São Paulo: Martins Fontes.

Vigotskii, L.S. (1988). Aprendizagem e desenvolvimento intelectual na idade escolar. In L. S. Vigotskii, A. R, Luria, \& A. N. Leontiev (Eds.), Linguagem, desenvolvimento e aprendizagem (M. P. Villalobos, Trad., pp. 103-118). São Paulo: Ícone.

Vygotski, L. S. (2000a). Análisis de las funciones psíquicas superiores. In Obras Escogidas (Vol.III, pp. 97-120). Madri: Visor.

Vygotski, L. S. (2000b). Estructura de las funciones psíquicas superiores. In Obras Escogidas (Vol. III, pp. 121-138). Madri: Visor.

Vygotski, L. S. (2000c). Génesis de las funciones psíquicas superiores. In Obras Escogidas (Vol. III, pp. 139-168). Madri: Visor.

Vygotski, L. S. (1996a). Paidología del Adolesente. In Obras Escogidas (Vol. IV, pp. 11-340). Madri: Visor.

Vygotski, L. S (1996b). Problemas de la Psicología Infantil. In Obras Escogidas (Vol. IV, pp. 249-387) Madri: Visor.

Zimmer, M., Jou, G. I. de, Sebastiany, C. M., Guimarães, E. R., Boechat, L. de C., Soares, T., \& Belmonte-de-Abreu, P. S. (2008). Avaliação neuropsicológica na esquizofrenia: Revisão sistemática. Revista de Psiquiatria do Rio Grande do Sul, 30(1), Recuperado de http://www.scielo.br/readcube/epdf. php?doi $=10.1590 /$ S0101-81082008000200005\&pid=S01018 $1082008000200005 \&$ pdf_path $=$ rprs/v30n 1 s0/v30n1a05s0.pdf

Zuanazzi, A. C., \& Ribeiro, R. L. (2015). Testes projetivos na avaliação psicológica da esquizofrenia: Uma revisão da literatura. Estudos Interdisciplinares em Psicologia, 6(2), 71-91. 